\title{
Accuracy and completeness of Mental Health Act forms applied to involuntary patients admitted to an inpatient psychiatric ward
}

This article was published in the following Dove Press journal: Clinical Audit

\author{
Stanislav Pasyk' \\ Jennifer Pikard ${ }^{2}$ \\ Dane Mauer-Vakil ${ }^{2}$ \\ Tariq Munshi ${ }^{2}$ \\ 'School of Medicine, Queen's \\ University, Kingston, ON, Canada; \\ ${ }^{2}$ Department of Psychiatry, Kingston \\ Health Sciences Centre, Queen's \\ University, Kingston, ON, Canada
}

\begin{abstract}
Background: The accuracy and completeness of Mental Health Act forms applied to involuntary patients in an inpatient unit is of paramount importance not only for legal but also for patient safety reasons within a hospital.
\end{abstract}

Materials and methods: This was a retrospective study of 250 patient charts from January 1, 2014 to March 31, 2014.

Results: Chart review provided a total of 224 Form 3, 4, 30, and 33 certificates with an overall error rate of $13.19 \%$ completion. Of those physicians who completed these certificates, the error rate was $11.63 \%$ if a resident physician were to complete and $19.23 \%$ if a staff physician were to apply the form.

Conclusion: As physicians, there is a legal and moral responsibility to ensure the accuracy of such documentation both ethically and practically as well as a responsibility to the patient and their rights under the Mental Health Act.

Keywords: Mental Health Act, Ontario, involuntary, inpatient

\section{Introduction}

The Ontario Mental Health Act provides an important medico-legal framework under which physicians can administer care and treatment to a patient on an involuntary basis where appropriate. ${ }^{1}$ This provincial legislation deals with several important inpatient issues including when an individual can be admitted to a psychiatric facility involuntarily, how an individual can be kept in hospital, notifying a patient that they have been found not mentally capable to consent to treatment of a mental disorder/manage property or examine/authorize disclosure of their medical record, and informing a patient of their right to appeal these decisions. ${ }^{2}$

Since 1978, the Ontario Mental Health Act has required that physicians complete specific documentation in order to detain patients for psychiatric assessment and to ensure they know their rights. The Act states that an Application for Psychiatric Assessment (Form 1) is only effective if it is signed and dated by the physician and requires the physician to provide a rationale for the application. ${ }^{3}$ In addition, the Act states that physicians are required to complete a Certificate of Involuntary Admission (Form 3) or Renewal (Form 4) after examining a patient and is of the opinion that the person is suffering from a mental disorder of such nature that the person is in need of the treatment provided in a psychiatric facility requiring involuntary admission to hospital. ${ }^{4}$

Physicians have a legal obligation and an ethical responsibility to ensure that documentation is accurate and complete to prevent invalid and unlawful detainment of patients which, in extreme circumstances, could lead to fines as large as $\$ 25,000 . .^{5} \mathrm{As}$ 
this process infringes on patients' civil liberties, it is of paramount importance to document the rationale for using these measures. The Ontario Mental Health Act forms explored in this study are described below in Table 1.

The College of Physicians and Surgeons of Ontario's policy statement on medical records outlines self-evaluation as an important tool for assessing documentation in medical records. The report discusses clinical auditing as a method for identifying the strengths and weaknesses of documentation in a system. ${ }^{6}$ The UK's Department of Health defines clinical audit as "the systematic, critical analysis of the quality of medical care, including the procedures used for diagnosis and treatment, the use of resources, and the resulting outcome and quality of life for the patient". ${ }^{7}$ A clinical audit can provide a review of current practices and procedures and compare these with current standards. With this type of rigorous selfevaluation, organizations are better positioned to identify areas where practice and knowledge can be improved and, in turn, to provide better services. ${ }^{8}$ The goal of conducting clinical auditing is to promote the quality improvement to occur where it will be most beneficial to improve patients outcomes.

The objectives of this study were to 1) assess the quality and accuracy of Ontario Mental Health Act documentation at Kingston General Hospital, a Canadian academic hospital, and 2) identify common errors and barriers to accurate documentation. This detailed analysis of errors in Ontario Mental Health Act documentation is valuable as medical education can be modified to target a reduction in common errors.

\section{Materials and methods}

Ethics was obtained by the Health Sciences Research Ethics Board at Queen's University at Kingston, Ontario. A single-center retrospective chart review was completed on all patients discharged from Kingston General Hospital who had been admitted to the inpatient psychiatric unit over a 3-month period (January 1, 2014 to March 31, 2014; n=250 charts). Patient consent was not required for this chart review from the ethics board as it was a retrospective review, patient confidentiality was maintained as no identifying data were present on the data collection sheet, the identifier for each eligible chart was deleted once the data were collected, and no master-code exists allowing research data to be linked with the identifiers. All Form 3, Form 4, Form 30, and Form 33 documentations pertaining to these hospital admissions were reviewed for accuracy and completeness. A total of 224 forms were evaluated. Errors in form completion were categorized into the following types:

- Incomplete fields: mandatory fields have been left blank.

- Error in fields: mandatory field have been filled with incorrect information.

- Ineligible physician: the physician completing the form is ineligible to do so, as they themselves completed a request for psychiatric evaluation (Form 1).

- Mismatched/missing accompanying form: patients placed on a Form 3 or Form 4 without an appropriate corresponding Form 30.

- Box A/Box B errors: errors in the completion of Box A or Box B criteria.

\section{Results \\ Total error rates in Mental Health Act forms}

Careful evaluation of the 224 forms completed at Kingston General Hospital inpatient psychiatry unit during the 3-month study interval revealed a total of 89 of these admissions to be involuntary as per applications for a Form 3. Of these, there were 19 extensions of involuntary stays on the unit as documented by applications of Form 4. Each of the certificates used in the process of involuntary admission to the psychiatric ward was audited for completeness and accuracy as per above. The overall error rate in all forms completed by physicians applied to patients during the study interval was $13.4 \%$.

Table I Descriptions of Ontario Mental Health Act forms

\begin{tabular}{|l|l|l|}
\hline Form & Form name & Purpose \\
\hline Form 3 & Certificate of Involuntary Admission & Admit the patient on an involuntary basis to hospital \\
\hline Form 4 & Certificate of Renewal & An extension of an involuntary admission to hospital \\
\hline Form 30 & $\begin{array}{l}\text { Notice to Patient under Subsection 38(I) of the Act } \\
\text { Form 33 }\end{array}$ & $\begin{array}{l}\text { A document given to the patient notifying them of his or her } \\
\text { involuntary admission }\end{array}$ \\
\hline
\end{tabular}




\section{Types of errors made}

Each mental health form, which contained errors and omissions, was categorized into one of the 5 broad categories of error (Table 2). Over half of all errors identified were associated with incorrect information (2.7\%) or frank omission of information (4.5\%) in the written fields of the forms, including the signature field. Another large source of error in form completion is in the documentation of Box A and Box $\mathrm{B}$ criteria $(2.7 \%)$. There was an error rate of $2.2 \%$ associated with missing or mismatched accompanying forms on the electronic medical record (example Form 3 without a Form 30 or 33 ). In $1.3 \%$ of the cases, the forms were filled out by the same physician who completed Form 1 (Application by Physician for Psychiatric Assessment) for that stay, rendering it invalid.

\section{Error rate by form type}

Of the four different Mental Health Act form types investigated in this study, Form $3(n=89)$ and Form $4(n=19)$ were found to contain the highest rate of errors $(16.8 \%$ and $15.8 \%$, respectively). Analysis of Form $30(\mathrm{n}=104)$ revealed a rate of $10.6 \%$, while $8.3 \%$ of Form 33 contained errors $(n=12)$. A summary of the results is shown in Table 3.

\section{Error rates by physician training level}

During study period, a large majority of forms were filed by resident physicians $(n=172)$ as compared with staff physicians $(n=52)$. Some differences emerged when comparing the errors between these two groups. Error rates varied by group, with rates $11.6 \%$ for residents and $19.2 \%$ for staff

Table 2 Error rates stratified by the type of error

\begin{tabular}{|l|l|l|}
\hline Type of error & $\mathbf{n}$ & Error rate (\%) \\
\hline Incomplete fields & 10 & 4.46 \\
\hline Error in fields & 6 & 2.68 \\
\hline Mismatched or missing accompanying form & 5 & 2.23 \\
\hline Box A/B errors & 6 & 2.68 \\
\hline Same physician as Form I & 3 & 1.34 \\
\hline
\end{tabular}

Table 3 Error rates stratified by Ontario Mental Health Act form type

\begin{tabular}{|l|l|l|l|}
\hline Form type & $\begin{array}{l}\text { Number of } \\
\text { forms applied }\end{array}$ & $\begin{array}{l}\text { Number of } \\
\text { forms containing } \\
\text { errors }\end{array}$ & $\begin{array}{l}\text { Error } \\
\text { rate (\%) }\end{array}$ \\
\hline Form 3 & 89 & 15 & 16.85 \\
\hline Form 4 & 19 & 3 & 15.79 \\
\hline Form 30 & 104 & $\mathrm{II}$ & 10.58 \\
\hline Form 33 & 12 & $\mathrm{I}$ & 8.33 \\
\hline All forms & 224 & 30 & 13.39 \\
\hline
\end{tabular}

psychiatrists (Table 4). Interestingly, the types of errors made by these two groups varied as well. Generally, resident physicians were more likely to omit information, submit incorrect information, and make errors related to the Box A and Box B criteria. Staff physicians were found to be more likely to have missing accompanying forms on record. Only staff psychiatrists were identified to have been ineligible to complete a Form $3(n=3)$ owing to the fact that they were the physician who completed the same patient's Form 1 preceding their admission (Table 5).

\section{Discussion}

It is of great importance when utilizing the Ontario Mental Health Act that physicians who treat involuntary patients provide proper documentation under the Act. This study is a clinical audit of only one Schedule 1 hospital facility with access to emergency psychiatry and an inpatient unit for the admission of psychiatric patients. While a smaller-scale retrospective chart review, the information presented is crucial to our understanding of not only errors in completion but of potential reasons and barriers to this important piece of legislation. This study demonstrated that when looking at Forms 3, 4, 30, and 33, there was an overall error rate of $13.4 \%$ and the most common errors were incomplete fields/ errors in those fields, Box A/B criteria, and missing Form 30. In $1.3 \%$ of cases, a Form 3 was completed by the same physician who completed a Form 1, which would deprive a patient of an independent second opinion. These factors could be explained by a multitude of factors not limited to: not taking the proper time to make sure the sections of each form are accounted for and perhaps complacency in administering forms - not due to the lack of caring and understanding but perhaps due to the frequency on an inpatient unit that forms are completed.

Errors with Box A/B criteria are important when evaluating factors essential to these components including if the person has received treatment for a mental health problem previously, the person showed clinical improvement as the result of the treatment, it is likely that the person will cause harm to him or herself or others, or to suffer significant

Table 4 Error rates stratified by the level of medical training

\begin{tabular}{|l|l|l|l|}
\hline $\begin{array}{l}\text { Level of training } \\
\text { of signatory of } \\
\text { certificate }\end{array}$ & $\begin{array}{l}\text { Number of } \\
\text { forms signed }\end{array}$ & $\begin{array}{l}\text { Number of } \\
\text { forms } \\
\text { containing } \\
\text { errors }\end{array}$ & $\begin{array}{l}\text { Error } \\
\text { rate (\%) }\end{array}$ \\
\hline Resident physician & 172 & 20 & 11.63 \\
\hline Staff physician & 52 & 10 & 19.23 \\
\hline
\end{tabular}


Table 5 Comparison of error types made by resident and staff physicians

\begin{tabular}{|l|l|l|l|l|}
\hline \multirow{2}{*}{ Types of errors } & \multicolumn{2}{l|}{ Resident physicians } & \multicolumn{2}{l|}{ Staff physicians } \\
\cline { 2 - 5 } & Number of errors & Error rate (\%) & Number of errors & Error rate (\%) \\
\hline Incomplete fields & 8 & 4.65 & 2 & 3.84 \\
\hline Error in fields & 4 & 2.90 & $\mathrm{I}$ & 1.92 \\
\hline Mismatched or missing accompanying form & 2 & 1.16 & 3 & 5.77 \\
\hline Box A/B errors & 6 & 2.91 & $\mathrm{I}$ & 1.92 \\
\hline Same physician as Form I & 0 & 0.00 & 3 & 5.77 \\
\hline
\end{tabular}

mental or physical deterioration or serious physical impairment, the person has been found to be incapable of consent and a substitute decision-maker consents to treatment on his or her behalf, and the person is not suitable for informal or voluntary admission. This, as well as the previous errors, can be substantially important for treatment decisions by physician, patient, and substitute decision maker.

Importantly with regard to overall errors, resident physicians were more likely to omit or submit incorrect information. They also were likely to make Box A/Box B errors; however, their overall rate of incorrect completion of forms was lesser than that of staff psychiatrists. This error may occur as a result of a smaller pool of staff physicians compared to residents at this one institution audited. Also, forms by staff physicians were more likely to have missing accompanying forms on record, which could be due to a multitude of factors including the hectic schedule of a staff psychiatrist, the assumption that a resident physician on their team might complete it, or perhaps coming from another province or country with a different Mental Health Act. With regard to missing Form 30, it is ethically important to make sure a patient is informed of their involuntary status, when it is extended, and how long the form may be extended to as it does infringe on a person's civil liberties.

Under the Ontario Mental Health Act, a patient may apply to have a Consent and Capacity Board (CCB) hearing if they disagree with their involuntary status. In Ontario, the CCB operates as an adjudicative tribunal created under the Health Care Consent Act of 1996. A CCB hearing decision is usually formed by a panel of three to five members with at least one psychiatrist, one lawyer, and one public member. The CCB conducts hearings under several provincial legislative acts; however, one of the most common applications before the CCB is to determine whether a patient who is detained involuntarily should have their decision upheld or rescinded. ${ }^{9}$ If this were to be so, and a patient wishes to challenge their involuntary status, literature describes that $\sim 18 \%$ of involuntary detentions are rescinded following a $\mathrm{CCB}$ hearing. ${ }^{10}$ However, the literature does not describe a numerical value for those rescinded primarily due to completion errors and therefore not an accurate reflection of the technical aspect of applying a form under the Mental Health Act.

\section{Conclusion}

With a detailed analysis of errors in Ontario Mental Health Act documentation at our local hospital, medical education can be modified to target a reduction in common errors. Several committees exist within the structure of the hospital system to improve and audit quality and safety issues with regard to patients, staff, and visitors, and it is the responsibility of these programs and physicians alike to identify barriers and improvement strategies. As well, there are ample education committees and time available to address these issues within the hospital setting, and specifically, introducing a process/checklist that ensures documentation is checked when one of these forms is completed is essential. This may be designated to nursing staff/unit aides who often notify the advisor of patient's rights. This audit cycle will be repeated following the above intervention to determine whether this change leads to better documentation. Bringing clinical audit information to any health care setting is only meant to improve the environment for both patients and health care providers, and it has been known that we all are continued learners, despite our profession.

\section{Disclosure}

The authors report no conflicts of interest in this work.

\section{References}

1. Canadian Mental Health Association [homepage on the Internet]. Mental health and addictions legislation; 2018. Available from: http:// ontario.cmha.ca/provincial-policy/criminal-justice/mental-health-andaddictions-legislation/. Accessed November 10, 2018.

2. Centre for Addiction and Mental Health [homepage on the Internet]. Understanding your rights; 2012. Available from: http://www.camh.ca/ en/hospital/visiting_camh/rights_and_policies/Pages/Understandingyour-rights.aspx. Accessed November 10, 2018.

3. Ontario Mental Health Act. (1990). R.S.O. 1990, c. M.7, s. 15 (5). 2000;c. 9 , s. 3 (6)

4. Ontario Mental Health Act. (1990). R.S.O. 1990;c. M.7, s. 20 (1.1, 5). 
5. Garside S, Levinson A, Kuziora S, Bay M, Norman G. Efficacy of teaching clinical clerks and residents how to fill out the form 1 of the mental health act using an e-learning module. Electronic J e-Learning. 2009;7(3):239-256.

6. College of Physicians and Surgeons of Ontario [homepage on the Internet]. Policy Statement \#4-12: Medical Records; 2006. Available from: http://www.cpso.on.ca/Policies-Publications/Policy/Medical-Records. Accessed November 10, 2018
7. Ellis BW, Sensky T. A clinician's guide to setting up audit. BMJ. 1991;302(6778):704-707.

8. Tsaloglidou A. Does audit improve the quality of care? Int $J$ Caring Sci. 2009;2(2):65.

9. Hiltz D, Szigeti A. A Guide to Consent and Capacity Law in Ontario. Canada: LexisNexis; 2006:266.

10. Moss JH, Redelmeier DA. Outcomes following appeal and reversal of civil commitment. Gen Hosp Psychiatry. 2010;32(1):94-98.

\section{Clinical Audit}

\section{Publish your work in this journal}

Clinical Audit is an international, peer-reviewed, open access journal focusing on the processes and outcomes of clinical audit in any area of healthcare. All aspects of patient care are addressed within the journal and practitioners from all disciplines are invited to submit their work. Areas covered include: Publication of audits; How an audit has changed practice;

Submit your manuscript here: https://www.dovepress.com/clinical-audit-journal

\section{Dovepress}

Practical tips on how to do audits and to avoid pitfalls; How audits have changed patient care; Calls and justifications for new audits. The manuscript management system is completely online and includes a very quick and fair peer-review system, which is all easy to use. Visit http://www.dovepress. com/testimonials.php to read real quotes from published authors. 